\title{
PRODUCTION OF NATURAL BUTYLATED HYDROXYTOLUENE AS AN ANTIOXIDANT BY FRESHWATER PHYTOPLANKTON ${ }^{1}$
}

\author{
Bakthavachalam Babu \\ Research Center for Biodiversity, Academia Sinica, Nankang, Taipei 115, Taiwan \\ and Jiunn-Tzong $W u^{2}$ \\ Research Center for Biodiversity, Academia Sinica, Nankang, Taipei 115, Taiwan \\ Institute of Ecology and Evolutionary Biology, National Taiwan University, Taipei 106, Taiwan
}

Butylated hydroxytoluene (BHT) is one of the synthetic antioxidant agents commonly used for food additives. In the present study, we determined that four freshwater phytoplankton, including a green alga (Botryococcus braunii Kütz.) and three cyanobacteria [Cylindrospermopsis raciborskii (Wolłosz.) Seenaya et Sabba Raju, Microcystis aeruginosa (Kütz.) and Oscillatoria sp.] were capable of producing this compound. Hexane extracts from all the studied species exhibited various degrees of antioxidative properties when they were tested with the $\beta$-carotene-linoleate ( $\beta$-CL) assay and the 2,2-diphenyl-1-picrylhydrazyl (DPPH) free-radical-scavenging assay. The highest antioxidant activity was observed in the crude extracts of $M$. aeruginosa and $B$. braunii, which displayed a similar activity to synthetic BHT. Gas chromatography/mass spectroscopy (GC-MS) analysis of the purified fractions revealed that the active compound was identical to synthetic BHT. Culturing under various irradiances gave rise to different magnitudes of BHT production in cyanobacterial cells, showing that more BHT was produced in the cells irradiated with a higher light intensity, and its production was irradiance dependent. Moreover, the quantity of cellular BHT displayed a positive correlation with the antioxidative activity of the tested species. The present study confirms the production of BHT in all four of the studied freshwater phytoplankton and suggests that these species constitute a potential source for producing natural BHT.

Key index words: butylated hydroxytoluene; cyanobacteria; green alga; irradiance; natural antioxidant

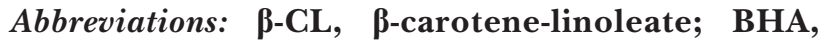
butylated hydroxyanisole; BHT, butylated hydroxytoluene; DM, dicyclopentenyloxyethyl methacrylate; DPPH, 2,2-diphenyl-1-picrylhydrazyl; EI, Electron Impact; FDA, Food and Drug Administration; GC-MS, gas chromatography-mass spectrometry; NIST, National Institute of Standards and Technology; PG, propyl gallate; ROS, reactive

\footnotetext{
${ }^{1}$ Received 6 December 2007. Accepted 21 May 2008.

${ }^{2}$ Author for correspondence: e-mail jtwu@gate.sinica.edu.tw.
}

oxygen species; SOD, superoxide dismutase; TBHQ, t-butylhydroquinone; TLC, thin layer chromatography

Reactive oxygen species (ROS), such as the superoxide anion, hydroxyl radicals, and hydrogen peroxide, cause lipid oxidation and thereby decrease the nutritional value and appearance of food. In addition, ROS are the major cause of qualitative decay of food, which leads to rancidity, toxicity, and destruction of major biochemical components that are important in metabolism (Park et al. 2005). Breimer (1990) stated that oxidative stress and ROS play an important role in the etiology and progression of major human degenerative diseases. Freeradical-mediated modifications of DNA, proteins, lipids, and small cellular molecules are associated with a number of pathological processes, including atherosclerosis, arthritis, diabetes, cataractogenesis, muscular dystrophy, pulmonary dysfunction, inflammatory disorders and ischemia-reperfusion tissue damage, and neurological disorders such as Alzheimer's disease (Frlich and Riederer 1995). Food manufacturers add many commercially available synthetic antioxidant agents, such as butylated hydroxyanisole (BHA), BHT, $t$-butylhydroquinone (TBHQ), and propyl gallate (PG) to food products to prevent lipid oxidation (Wanita and Lorenz 1996). In addition, ingestion of these synthetic antioxidants may decrease the risk of developing the chronic diseases mentioned above (Gale et al. 1995, Hoffman and Garewal 1995). However, the U.S. Food and Drug Administration (FDA) has restricted the use of synthetic antioxidants in food products because of their suspected carcinogenicity (Ito et al. 1986, Wattenberg 1986, Madhavi and Salunkhe 1995, Hettiarachy et al. 1996). Therefore, the search for natural antioxidants as a substitute for synthetic ones has become an important goal for the food technology industry in recent years.

Both algae and cyanobacteria are considered to be commercially potential sources of antioxidants 
(Fujimoto and Kaneda 1984, Cahyana et al. 1992, Pinero Estrada et al. 2001). Although most photosynthetic organisms are exposed to a combination of light and high oxygen concentrations, which leads to the formation of free radicals and other strong oxidizing agents, they seldom suffer from serious photodynamic and DNA damage in vivo, suggesting that their cells contain protective antioxidative mechanisms and compounds (Sukenik et al. 1993, Matsukawa et al. 1997, Sinha et al. 2003, Park et al. 2005, Sigaud-Kutner et al. 2005). Recently, researchers have isolated various types of antioxidant compounds from different algal species, including fucoxanthin in Hijikia fusiformis (Yan et al. 1999); phycocyanin and phycocyanobilin in Spirulina platensis and Aphanizomenon flos-aquae (Bhat and Madyastha 2000, 2001, Hirata et al. 2000, Romay and Gonzalez 2000, Benedetti et al. 2004); phenolic acids, tocopherols, and $\beta$-carotene in Spirulina maxima (Miranda et al. 1998); fatty acids, polyphenols, and phlorotannin in Sargassum kjellamanianum, S. siliquastrum, Rhodomela confervoides, Symphjocladia latiuscula, and Kappaphycus alvarezzi (Yan et al. 1996, Lim et al. 2002, Huang and Wang 2004, Fayaz et al. 2005); lutein in Botryococcus braunii (Rao et al. 2006); and carotenoids in Dunaliella salina (Ben-Amotz and Avron 1988, Neuman et al. 1999, Levy et al. 2000, Herrero et al. 2006). Our preliminary tests found that certain bloom-forming algae or cyanobacteria exhibited strong antioxidation activity, possibly because they have to survive in strong light and oxidative conditions when they float on the water surface (data not shown). In the present study, we further assayed the antioxidant capability of four bloom-forming species, namely, B. braunii, C. raciborskii, M. aeruginosa, and Oscillatoria sp., by means of the $\beta$-CL model assay and the DPPH free-radicalscavenging assay. The crude extracts were partially purified through thin-layer chromatography (TLC) and then subsequently by GC-MS to identify the antioxidant compounds. Synthetic compounds were used for comparison.

\section{MATERIALS AND METHODS}

Chemicals. Linoleic acid, Tween 40 (polyoxyethylene sorbitan monopalmitate), BHT, DPPH, dicyclopentenyloxyethyl methacrylate $(\mathrm{DM})$, and $\beta$-carotene were purchased from Sigma Chemicals Co. (St. Louis, MO, USA). All the other organic chemicals and the silica gel TLC plate $\left(60 \mathrm{~F}_{254}\right.$, $20 \times 20 \mathrm{~cm})$ used in this study were of analytical grade from Merck (Darmstadt, Germany).

Samples for tests. Four freshwater algal strains were used for the present studies: a green alga, $B$. braunii, and three species of cyanobacteria, C. raciborskii, M. aeruginosa, and Oscillatoria sp. The cell mass of B. braunii (Trebouxiophyceae) was collected by a plankton net (pore size $55 \mu \mathrm{m}$ ) in Li-Yu Lake $\left(23^{\circ} 55^{\prime} 45^{\prime \prime} \mathrm{N}, 121^{\circ} 30^{\prime} 33^{\prime \prime} \mathrm{E}\right)$, Taiwan, when it bloomed in the spring of 2006. The cyanobacteria species were collected from water reservoirs in Taiwan when they formed water blooms in the summer of 2004. After isolation, the three cyanobacteria were mass-cultured in an inorganic medium (Jüttner et al.
$1983)$ in the laboratory at $25 \pm 1{ }^{\circ} \mathrm{C}$ under continuous illumination with $75 \mu \mathrm{mol}$ photons $\cdot \mathrm{m}^{-2} \cdot \mathrm{s}^{-1}$ and aeration with compressed air.

Culture conditions. Before the experiments, the strains were grown exponentially by repeated (at least two times) inoculation into fresh medium. During the exponential phase of each strain, $50 \mathrm{~mL}$ inoculums were transferred to $2 \mathrm{~L}$ medium (in triplicates) and incubated under constant illumination (by daylight fluorescent lamps) at three different irradiances: 25,75 , and $150 \mu \mathrm{mol}$ photons $\cdot \mathrm{m}^{-2} \cdot \mathrm{s}^{-1}$. The cell mass was harvested by centrifugation (himac-CR21G centrifuge, Hitachi High-Technologies Co. Ltd., Minato-Ku, Tokyo, Japan) at $10,000 \mathrm{~g}$ for $15 \mathrm{~min}$. All of the collected cell masses were lyophilized and stored at $-70^{\circ} \mathrm{C}$ for further use.

Extraction of algal samples. One gram of each of the dried algal samples was extracted with hexane at room temperature and kept in a shaker. The extraction was repeated until the sample became colorless. The extracts were condensed in a vacuum rotary evaporator (Rotavapor-R, Buchi Labortechnik AG, Postfach, Flawil, Switzerland) and dried using a stream of nitrogen gas.

Partial purification of extracts by TLC. Hexane extracts of samples were used for partial purification through silica gel TLC. The dried crude extracts were dissolved in a small volume of chloroform:methanol $(1: 1 \mathrm{v} / \mathrm{v})$, applied to the TLC plates, and chromatographed using acetone:methanol:water (40:20:1 $\mathrm{v} / \mathrm{v} / \mathrm{v}$ ) as the developing solvents. Bands with different Rf values were scraped out separately and extracted according to Bligh and Dyer (1959) and centrifuged. The desired ratio of solvents was obtained by adding the appropriate volume of chloroform and water to arrive at a final ratio of chloroform:methanol:water $(1: 1: 0.9 \mathrm{v} / \mathrm{v} / \mathrm{v})$. The chloroform extracts were evaporated to dryness. The partially purified dried fractions of all samples were tested for antioxidant activity and analyzed for chemical constituents by GC-MS.

GC-MS analysis. The Agilent GC-MS system, which consists of a GC-6890N equipped with a 5975 MSD and installed with an HP-5 MS ultra low-bleed 5\%-phenyl column (30 m $\times$ $0.32 \mathrm{~mm} \times 25 \mu \mathrm{m}$; J\&W Scientific, Folsom, CA, USA), was used for quantitative and qualitative analyses in this study. The oven temperature was programmed to rise from $70^{\circ} \mathrm{C}(2 \mathrm{~min}$ isothermal) to $250^{\circ} \mathrm{C}$ at a ramp of $10^{\circ} \mathrm{C}$ per min and held at $250^{\circ} \mathrm{C}$ for $5 \mathrm{~min}$. The injector temperature was kept at $250^{\circ} \mathrm{C}$. The Electron Impact (EI) mass spectra were obtained with $70 \mathrm{eV}$ electron energy, and the MS spectra were scanned in the mass range of $\mathrm{m} / \mathrm{z}$ from 50 to 550 . Helium gas was used as the carrier gas at a flow rate of $1 \mathrm{~mL} \cdot \mathrm{min}^{-1}$. One microliter of the algal crude extract and the partially purified TLC fraction sample were injected into the injector using the splitless mode. DM was used as an internal standard. Identification of compounds was based on comparison of their retention indices and mass spectra with those of the Wiley and National Institute of Standards and Technology (NIST) mass spectral databases and a synthetic BHT standard under the same chromatographic conditions.

Antioxidant assay. The antioxidant activity of the crude extracts and the partially purified fractions of the algal and cyanobacterial samples was determined using the DPPH freeradical-scavenging assay and the $\beta-\mathrm{CL}$ assay. A synthetic BHT standard was used as the control.

$\beta-C L$ assay. The antioxidant activity of the studied samples was evaluated by a $\beta$-CL assay model with a slight modification (Jayaprakash et al. 2001). A mixture of $0.2 \mathrm{mg}$ of $\beta$-carotene, $20 \mathrm{mg}$ of linolenic acid, and $200 \mathrm{mg}$ of Tween 40 (polyoxyethylene sorbitan monopalmitate) was mixed with $0.5 \mathrm{~mL}$ of chloroform. The chloroform was then removed at $40^{\circ} \mathrm{C}$ with a vacuum rotary evaporator. After the removal of chloroform, the residue was immediately diluted with $10 \mathrm{~mL}$ of distilled 
water and stirred well for 1-2 min to facilitate complete mixing. The emulsion was brought up to $50 \mathrm{~mL}$ with oxygenated water $(40 \mathrm{~mL})$.

Four-milliliter aliquots of the emulsion were transferred into different test tubes containing $0.2 \mathrm{~mL}$ of crude extracts $(100$, 200 , and $300 \mu \mathrm{g} \cdot \mathrm{mL}^{-1}$, respectively). For comparison, a BHT control prepared at the same concentrations in hexane was assayed. The control contained $0.2 \mathrm{~mL}$ of hexane and $4 \mathrm{~mL}$ of the above emulsion. The test tubes were heated at $50^{\circ} \mathrm{C}$ in a water bath, and the initial $(t=0)$ absorbance at $470 \mathrm{~nm}$ of the test tube was measured. The measurement of absorbance was continued at intervals of $30 \mathrm{~min}$ until the color of $\beta$-carotene disappeared in the control tubes $(t=120 \mathrm{~min})$. A mixture prepared as above without $\beta$-carotene was used as the blank. All determinations were carried out in triplicate. Antioxidant activity (AA) was calculated based on the formula:

$$
\mathrm{AA}=100\left[1-\left(A_{0}-A_{t}\right) /\left(A_{0}^{o}-A_{t}^{o}\right)\right]
$$

where $A_{0}$ and $A_{0}{ }^{\circ}$ are the absorbance values measured at time zero of the incubation for the test samples and the control, respectively, and $A_{t}$ and $A_{t}^{\circ}$ are the absorbance values measured in the test sample and the control, respectively, after incubation for 120 min.

DPPH free-radical-scavenging assay. The free-radical-scavenging activities of the crude extracts and partially purified fractions from different samples as well as the BHT control were evaluated following the procedure described by Singh et al. (2002). Three different concentrations, 100,200 , or $300 \mu \mathrm{g}$ of the crude extract of studied samples and the control were added to a test tube and brought up to a volume of $500 \mu \mathrm{L}$ by adding methanol. Five milliliters of a methanolic solution of $0.1 \mathrm{mM} \mathrm{DPPH}$ was added to these tubes and shaken vigorously. The tubes were allowed to remain at $27^{\circ} \mathrm{C}$ for $20 \mathrm{~min}$. The control was prepared without any extract, and methanol was used as the blank. Changes in absorbance at $517 \mathrm{~nm}$ of the samples were measured. The freeradical-scavenging activity was expressed as the percentage of inhibition and was calculated using the following formula: Percentage of radical scavenging activity $=($ control OD-sample $\mathrm{OD} /$ control OD) $\times 100$. For each of the experiments, three replicates were maintained. The mean values of each treatment were compared using analysis of variance (ANOVA) with Tukey's test and correlation coefficient analysis (Pearson $r$ ). All statistical analyses were performed by GraphPad InStat, version 3.00 (San Diego, CA, USA).

\section{RESULTS}

Antioxidative activity assayed by the $\beta-C L$ method. All four species studied showed a dose-response relation in their ability to inhibit the discoloration of $\beta$-carotene: the higher the dose, the greater their inhibition. Among them, M. aeruginosa and B. braunii were more effective than the other two species in inhibiting the discoloration of $\beta$-carotene (Fig. 1a). At a concentration of $100 \mu \mathrm{g} \cdot \mathrm{mL}^{-1}$, the extracts of M. aeruginosa and B. braunii inhibited $\sim 40.2 \%$ and $34.6 \%$ of $\beta$-carotene bleaching, respectively, compared to $\sim 50.4 \%$ for the BHT control. C. raciborskii $(29.0 \%)$ and Oscillatoria sp. $(24.8 \%)$ had lower antioxidant activities (Fig. 1a). One-way ANOVA showed significant differences between tested samples, and a positive correlation was observed between the concentration and antioxidant activity (Table 1). A similar trend was observed when the treated concentrations were elevated to 200 or $300 \mu \mathrm{g} \cdot \mathrm{mL}^{-1}$.
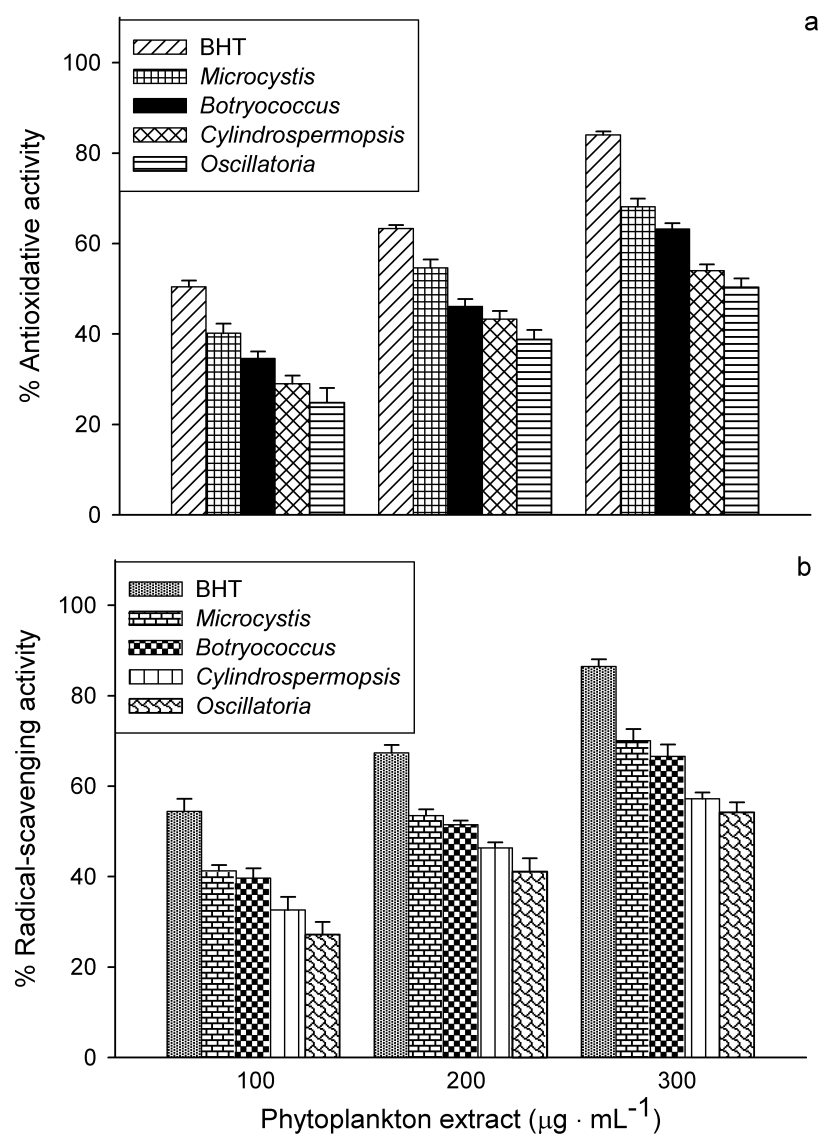

FIG. 1. (a) Antioxidative activity assayed by the $\beta$-CL method and (b) free-radical-scavenging activity assayed by the DPPH method at different doses of extracts from four algal species in comparison with synthetic BHT. Bars indicate mean \pm SD $(n=3)$. $\beta$-CL, $\quad \beta$-carotene-linoleate; BHT, butylated hydroxytoluene; DPPH, 2,2-diphenyl-1-picrylhydrazyl.

TABle 1. One-way ANOVA for $\beta$-CL and DPPH assays of the samples $\left(100 \mu \mathrm{g} \cdot \mathrm{mL}^{-1}\right)$.

\begin{tabular}{|c|c|c|}
\hline & $\beta$-CL assay & DPPH assay \\
\hline Samples & q & $q$ \\
\hline BHT vs. Microcystis & $9.265^{\mathrm{a}}$ & $9.138^{\mathrm{a}}$ \\
\hline BHT vs. Botryococcus & $14.449^{\mathrm{a}}$ & $10.256^{\mathrm{a}}$ \\
\hline BHT vs. Cylindrospermopsis & $18.788^{\mathrm{a}}$ & $15.141^{\mathrm{a}}$ \\
\hline BHT vs. Oscillatoria & $21.848^{\mathrm{a}}$ & $18.911^{\mathrm{a}}$ \\
\hline Microcystis vs. Botryococcus & $5.184^{\mathrm{c}}$ & $1.118^{\mathrm{d}}$ \\
\hline Microcystis vs. Cylindrospermopsis & $9.523^{\mathrm{a}}$ & $6.003^{c}$ \\
\hline Microcystis vs. Oscillatoria & $12.582^{\mathrm{a}}$ & $9.772^{\mathrm{a}}$ \\
\hline Botryococcus vs. Cylindrospermopsis & $4.339^{\mathrm{d}}$ & $4.885^{\mathrm{c}}$ \\
\hline Botryococcus vs. Oscillatoria & $7.399^{\mathrm{b}}$ & $8.654^{\mathrm{a}}$ \\
\hline Cylindrospermopsis vs. Oscillatoria & $3.769^{\mathrm{d}}$ & $3.769^{\mathrm{d}}$ \\
\hline
\end{tabular}

${ }^{\mathrm{a}} P<0.001$, extremely significant; ${ }^{\mathrm{b}} P<0.01$, very significant; ${ }^{\mathrm{c}} P<0.05$, significant; ${ }^{\mathrm{d}} P>0.05$, not significant. ANOVA, analysis of variance; $\beta$-CL, $\beta$-carotene-linoleate; DPPH, 2,2-diphenyl-1-picrylhydrazyl.

Radical-scavenging activity assayed by the DPPH method. Samples from all of the studied species exhibited radical-scavenging activity (Fig. 1b). Among them, the extracts of $M$. aeruginosa (41.24\%) and 
B. braunii (39.63\%) exhibited higher activity than those of C. raciborskii (32.6\%) and Oscillatoria sp. $(27.17 \%)$. In addition, the activity increased with an elevated test dose, independently of the kinds of samples (Fig. 1b), and followed a trend similar to that of the $\beta$-CL method (Fig. 1a). Statistical analysis by one-way ANOVA showed significant differences between the tested samples, and a positive correlation was observed between the concentration and radical-scavenging activity (Table 1 ).

Purification and identification of antioxidants. The crude extracts of the four species were purified using the silica gel TLC plates with acetone:methanol:water $(40: 20: 1 \mathrm{v} / \mathrm{v} / \mathrm{v})$ as the developing solvent. Six fractions were obtained for C. raciborskii (C1-C6), M. aeruginosa (M1-M6), and Oscillatoria sp. (O1-O6), and five were obtained for B. braunii (B1-B5). Of these fractions, only one from each of the studied species-fractions M5, B4, C5, and O4-exhibited antioxidant activity when subjected to the DPPH assay.

The gas chromatogram of the $\mathrm{B} 5$ fraction of B. braunii exhibited a distinct peak with a retention time identical to that of the synthetic BHT compound (Fig. 2, a and b). The same result was obtained for M. aeruginosa (fraction M5), C. raciborskii (fraction C5), and Oscillatoria sp. (fraction O4) by GC-MS spectra. Figure 2c shows the gas chromatogram and the mass spectrum of the fragmentation pattern of the M5 fraction of M. aeruginosa. The fractions from the other two cyanobacteria displayed the same retention time on the gas chromatograms as that of $M$. aeruginosa.

The peak identities were further confirmed by the GC-MS spectra. The GC-MS spectra of all the fractions of the studied samples were acquired in the full-scan mode in the mass range of $\mathrm{m} / \mathrm{z}$ from 50 to 550. The corresponding full-scan mass spectrum obtained for our purified compound in the fraction B5 of B. braunii is shown in Figure 3a. The mass spectrum of our purified compound exhibited a molecular ion $[\mathrm{M}]^{+}$at $\mathrm{m} / z=220$. The base peak was observed at $\mathrm{m} / z=205$ mainly due to loss of a methyl group corresponding with [M-CH3 $^{+}$and a second fragment at $\mathrm{m} / z=177$ corresponding with $\left[\mathrm{M}-\mathrm{C}_{2} \mathrm{H}_{3} \mathrm{O}\right]^{+}$. The fragmentation pattern of this purified compound was identical to the mass spectrum of a synthetic BHT compound (Fig. 3b) and the data published in the NIST library for the BHT compound. The fragmentation patterns of this $[\mathrm{M}]^{+}$ion peak at $\mathrm{m} / z=205$ was identical to all the fractions of M. aeruginosa (Fig. 3c), C. raciborskii, and Oscillatoria sp.

Effect of different irradiances on BHT production. Three cyanobacteria were cultured under three irradiance conditions: 25, 75, and $150 \mu \mathrm{mol}$ photons $\cdot \mathrm{m}^{-2} \cdot \mathrm{s}^{-1}$, to study the relationship between the production of BHT and irradiance. Figure 4a showed that all three of the cyanobacteria had the highest
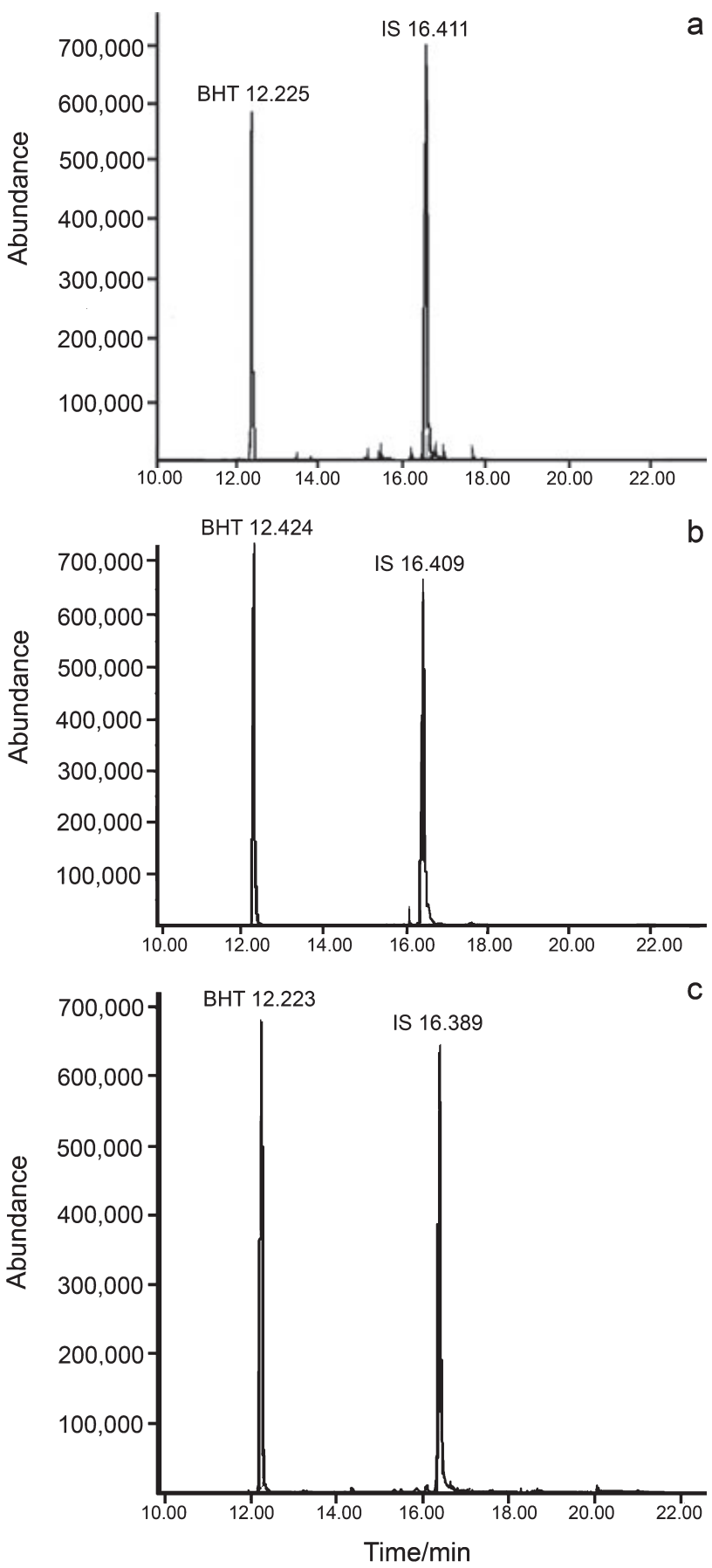

Fig. 2. Total ion chromatogram analysis of (a) the B5 fraction of Botryococcus braunii showing retention time (RT) (12.225) identical to synthetic BHT, (b) synthetic BHT showing RT of 12.242, and (c) the M5 fraction of Microcystis aeruginosa showing RT (12.223) identical to synthetic BHT. DM serves as the internal standard (IS). BHT, butylated hydroxytoluene; DM, dicyclopentenyloxyethyl methacrylate.

yield of biomass at $75 \mu \mathrm{mol}$ photons $\cdot \mathrm{m}^{-2} \cdot \mathrm{s}^{-1}$, followed by the yields at 150 and $25 \mu \mathrm{mol}$ photons $\cdot \mathrm{m}^{-2} \cdot \mathrm{s}^{-1}$. Among the three cyanobacteria, M. aeruginosa exhibited a higher biomass yield $(5.8 \pm 0.68 \mathrm{~g})$ than the other two species. 

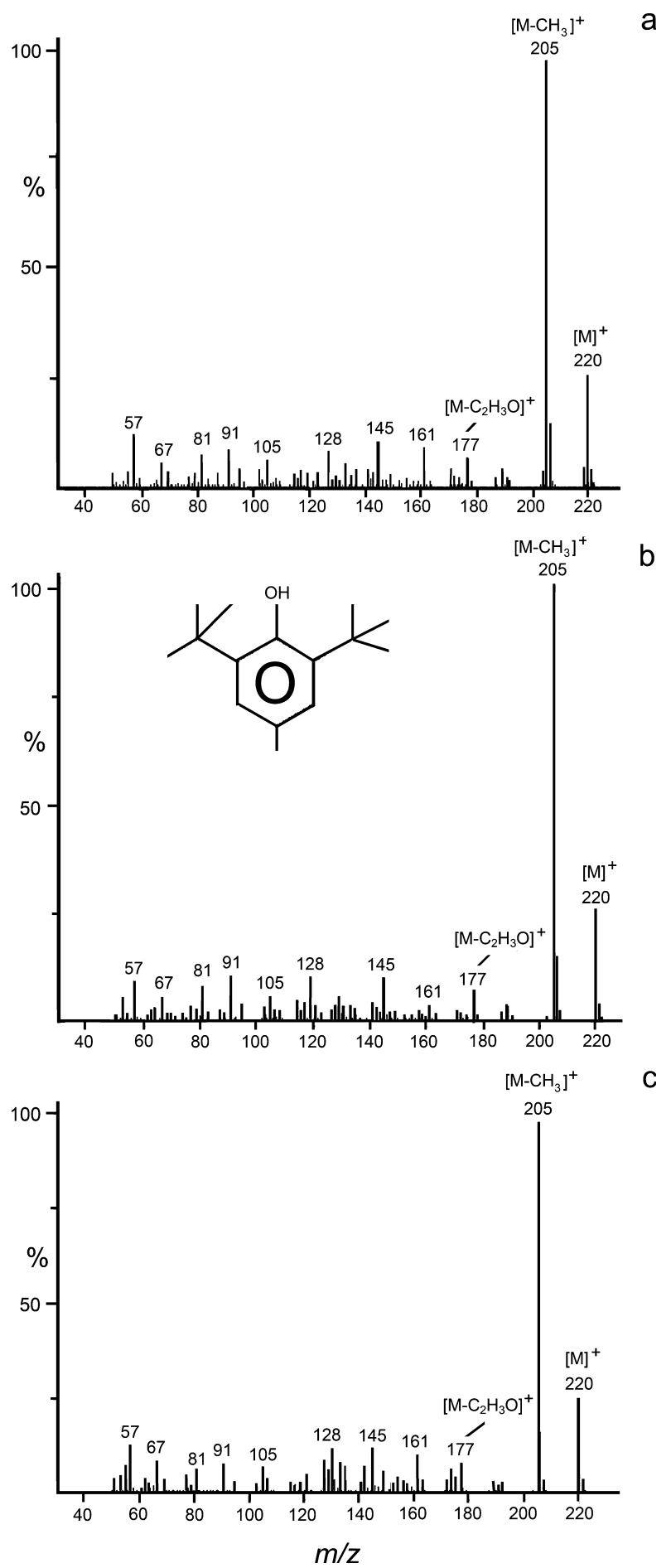

Fig. 3. Mass spectrum showing the fragmentation pattern of (a) the B5 fraction of Botryococcus braunii, (b) synthetic BHT, and (c) the M5 fraction of Microcystis aeruginosa. BHT, butylated hydroxytoluene.

The content of BHT quantified by gas chromatographic analysis was compared with respect to irradiance. The highest production of BHT was measured for those cultures growing under the highest irradiance (i.e., $150 \mu \mathrm{mol}$ photons $\cdot \mathrm{m}^{-2} \cdot \mathrm{s}^{-1}$ ) (Fig. $4 \mathrm{~b}$ ).
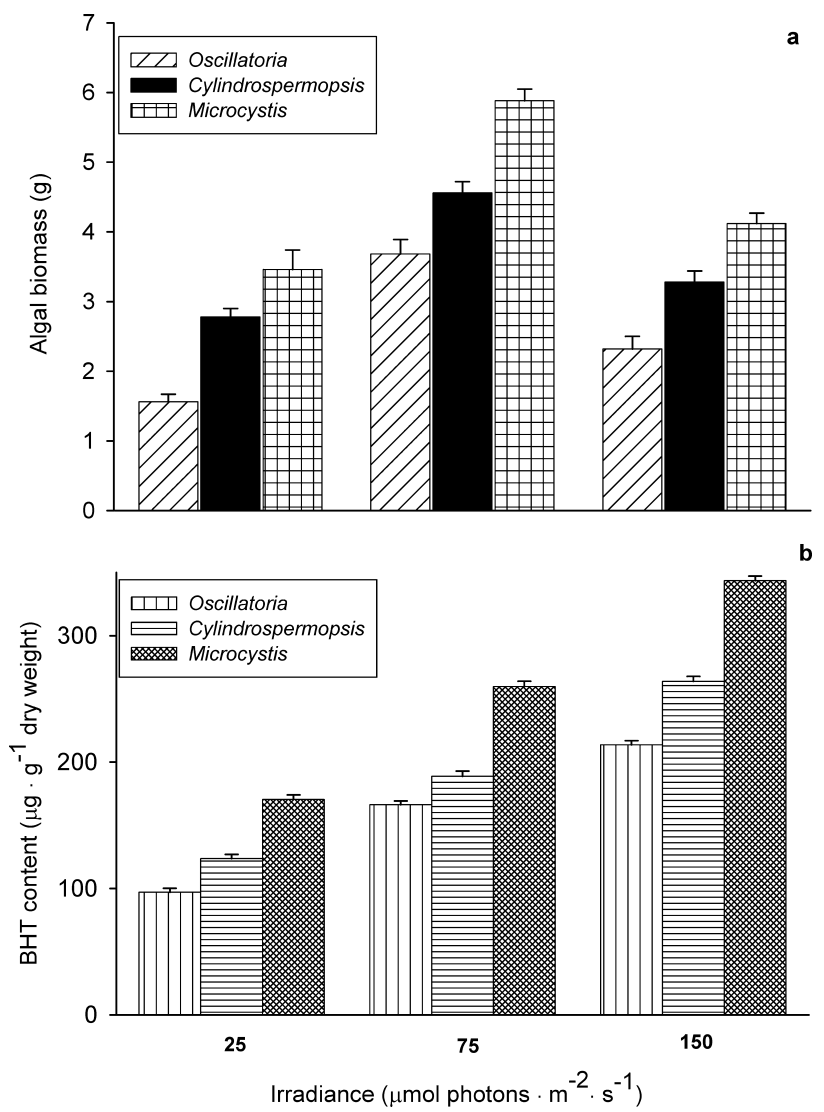

Fig. 4. Growth and BHT-production of three cyanobacteria under three different irradiances. (a) Biomass production; (b) BHT content. Bars indicate mean \pm SD $(n=3)$. BHT, butylated hydroxytoluene.

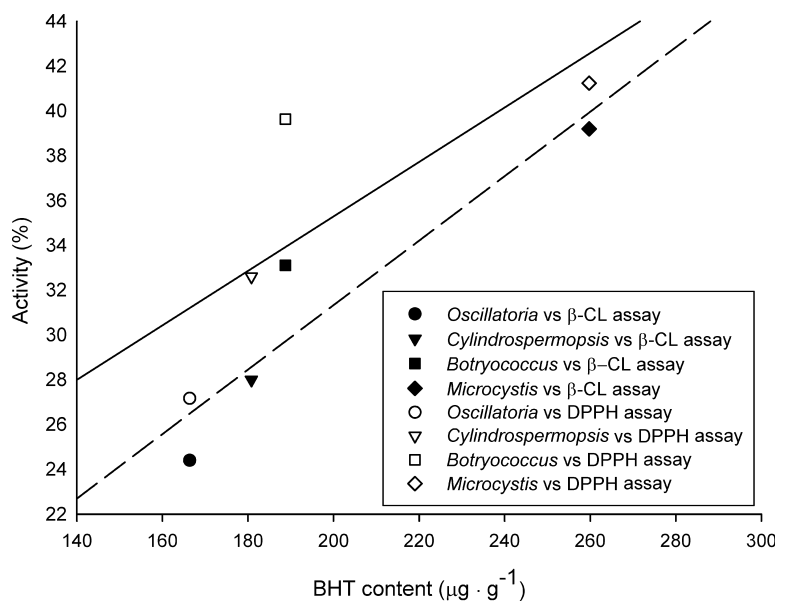

FIG. 5. Plot of the produced quantity of BHT in four studied species as a function of antioxidative activities assayed by the $\beta$-CL method and the DPPH method. The regressions for $\beta$-CL and DPPH methods are shown by broken and solid lines, respectively. $\beta$-CL, $\beta$-carotene-linoleate; BHT, butylated hydroxytoluene; DPPH, 2,2-diphenyl-1-picrylhydrazyl.

The same tendency was observed in all three cyanobacteria. A positive correlation (with $r \sim 0.974-0.998$, $P<0.0001)$ was observed between the irradiance 
and BHT content, suggesting the dependence of the production of BHT on irradiance.

To further elucidate the role of cellular BHT in the antioxidative capability of organisms, the BHT content in all of the studied species was plotted against the antioxidative activity assayed either by the $\beta$-CL method or by the DPPH method. Figure 5 shows that the species that produced more BHT displayed a higher antioxidative activity, independently of the assay methods. Apparently, a positive correlation exists between antioxidative activity and the quantity of BHT produced in all of the four studied species.

\section{DISCUSSION}

Blooms of Microcystis, Cylindrospermopsis, and Oscillatoria are commonly associated with toxic events in the aquatic environment due to production of compounds such as anatoxins, cylindrospermopsins, and microcystins (Falconer 2001). These toxins cause mortality in animals as well as human illness (Carmichael and Falconer 1993, Ueno et al. 1996). Oxidative damage might be involved in the toxic effects of microcystins, because increased lipid peroxidation and oxidative stress generation have been observed in animals or cells exposed to microcystins (Ding et al. 2000, Botha et al. 2004, Bouaicha and Maatouk 2004, Li et al. 2005). The antioxidant potential is assumed to be attributable to their defense mechanism acquired against the toxic substances, or in preventing photodynamic and DNA damage caused by exposure to varying light intensities and high oxygen concentrations (Sukenik et al. 1993, Matsukawa et al. 1997, Sinha et al. 2003, Sigaud-Kutner et al. 2005).

The $\beta$-CL assay was applied to determine the antioxidation activity of B. braunii, C. raciborskii, $M$. aeruginosa, and Oscillatoria sp. The $\beta$-CL assay illustrated that the extracts of all four tested species inhibited the discoloration of $\beta$-carotene, hence displaying positive antioxidation activity. The discoloration of $\beta$-carotene is a free-radical-mediated process resulting from the hydroperoxide donated by linoleic acid. The free radicals donated by linoleic acid strike the highly unsaturated $\beta$-carotene molecules to cause loss of its double bonds via oxidation. As a result, $\beta$-carotene molecules lose their chromophore and their characteristic orange color, which can be monitored spectrophotometrically (Jayaprakash et al. 2001). The presence of an antioxidative compound, however, can hinder $\beta$-carotene bleaching by neutralizing, to some degree, the linoleate free radical and other free radicals formed in this system: the slower the discoloration, the stronger the antioxidant activity for a test species.

The DPPH assay exhibited radical-scavenging activity in all the four algal species. The hydrogendonating ability of the extracts is responsible for the scavenging activity (Shimada et al. 1992). Free radicals in food are known to induce auto-oxidation of unsaturated lipids (Kaur and Perkins 1991), and antioxidant compounds are believed to intercept the free-radical chain of oxidation and to donate hydrogen from the phenolic hydroxyl groups, thereby forming a stable end product that does not initiate further oxidation of the lipid (Sherwin 1978). The results of the present study suggest that the extracts of all four freshwater algae are free-radical inhibitors and primary antioxidants that can react with free radicals. Of the four species, the extracts of $M$. aeruginosa and $B$. braunii exhibited higher antioxidant activity than those of C. raciborskii and Oscillatoria sp. The antioxidant activity was observed to increase with an elevated test dose.

Based on the GC-MS analysis, the antioxidant compound observed in the algal species is identical to that of a synthetic BHT, as it not only shared the same retention time in the total ion chromatogram but also had similar mass spectral data. The present study thus revealed that all the four algal species produce a natural BHT that exhibits antioxidant activity similar to that of synthetic BHT. Thus, these algal species have the potential to be used as an alternative commercial source for BHT production.

Khotimchenko and Yakovleva (2004) reported the production of ROS in algae under high irradiances. In general, algae show two major types of defense mechanism against ROS, the enzymatic and the nonenzymatic antioxidant systems. The enzymatic mechanism studied in Anabaena, Microcystis, and Nodularia showed an increase in superoxide dismutase (SOD) and ascorbate peroxidase activity at high irradiance (Canini et al. 1991, 1996, 1998, 2001). The nonenzymatic antioxidant mechanism observed in Ulva fenestrata shows variations in the lipid composition at different irradiances, which protect the cell from photooxidation (Khotimchenko and Yakovleva 2004). Tedesco and Duerr (1989) found that high irradiance $\left(1,411 \mu \mathrm{mol}\right.$ photons $\left.\cdot \mathrm{m}^{-2} \cdot \mathrm{s}^{-1}\right)$ increased total lipids and the percent composition of polyunsaturated fatty acids, such as $\beta$-linolenic acid, in Spirulina platensis. Walsh et al. (1997) reported that the variation in the fatty acid composition in Microcystis aeruginosa was due to high levels of irradiance, which occurred as a cellular response to reduce the susceptibility of the algal membranes to photooxidation. In the present study, high irradiance lowered the biomass production but induced a higher production of BHT. Apparently, the amount of BHT produced by the cells is related to irradiance, rather than to growth rate or biomass. Thus, the production of BHT exhibits a light dependency and is considered to protect the cells from photooxidation.

In conclusion, the extracts of the four species studied exhibited moderate to strong antioxidant activities. The variation in activity was related to the quantity of BHT produced in the cells. Both $M$. aeruginosa and B. braunii contained similar amounts of this compound and exhibited an antioxidant activity comparable to that of synthetic 
BHT. The quantity of BHT produced was related to the irradiation intensity of the growth conditions and exhibited a positive correlation with the degree of antioxidative activity of the tested species. To the best of our knowledge, this is the first report of the occurrence of BHT in freshwater algae. This study suggests that these algae have potential for the production of natural BHT.

Ben-Amotz, A. \& Avron, M. 1988. The wavelength dependence of massive of carotene synthesis in Dunaliella bardawil. J. Phycol. 25:178-83.

Benedetti, S., Benvenuti, F., Pagliarani, S., Francogli, S., Scoglio, S. \& Canestrari, F. 2004. Antioxidant properties of a novel phycocyanin extract from the blue-green alga Aphanizomenon flosaquae. Life Sci. 75:2353-62.

Bhat, V. B. \& Madyastha, K. M. 2000. C-phycocyanin: apotent peroxyl radical scavenger in vivo and in vitro. Biochem. Biophys. Res. Commun. 275:20-5.

Bhat, V. B. \& Madyastha, K. M. 2001. Scavenging of peroxynitrite by phycocyanin and phycocyanobilin from Spirulina platensis: protection against oxidative damage to DNA. Biochem. Biophys. Res. Commun. 285:262-6.

Bligh, E. G. \& Dyer, W. J. 1959. A rapid method of total lipid extraction and purification. Can. J. Biochem. Physiol. 37: 911-7.

Botha, N., Gehringer, M. M., Downing, T. G., van de Venter, M. \& Shephard, E. G. 2004. The role of microcystin-LR in the induction of apoptosis and oxidative stress in $\mathrm{CaCo}_{2}$ cells. Toxicon 43:85-92.

Bouaicha, N. \& Maatouk, I. 2004. Microcystin-LR and nodularin induce intracellular glutathione alteration, reactive oxygen species production and lipid peroxidation in primary cultured rat hepatocytes. Toxicol. Lett. 148:53-63.

Breimer, L. H. 1990. Molecular mechanisms of oxygen radical carcinogenesis and mutagenesis: the role of DNA base damage. Mol. Carcinog. 3:188-97.

Cahyana, A. H., Shuto, Y. \& Kinoshita, Y. 1992. Pyropheophytin $a$ as an antioxidative substance from the marine alga, arame (Eisenia bicyclis). Biosci. Biotechnol. Biochem. 56:1533-5.

Canini, A., Albertano, P. \& Grilli Caiola, M. 1998. Localization of Fe-containing superoxide dismutase in cyanobacteria from the Baltic Sea: depth and light dependency. New Phytol. 139:24754.

Canini, A., Albertano, P., Leonardi, D., Di Somma, D. \& Grilli Caiola, M. 1996. Superoxide dismutase in cyanobacteria of the Baltic Sea. Algol. Stud. 83:129-43.

Canini, A., Galiazzo, F., Rotilio, G. \& Grilli Caiola, M. 1991. Superoxide dismutase in the symbiont Anabaena azollae Strasb. Plant Physiol. 97:34-40.

Canini, A., Leonardi, D. \& Grilli Caiola, M. 2001. Superoxide dismutase activity in the cyanobacterium Microcystis aeruginosa after surface bloom formation. New Phytol. 152:107-16.

Carmichael, W. W. \& Falconer, I. R. 1993. Diseases related to freshwater blue-green algal toxins and control measures. In Falconer, I. [Ed.] Algal Toxins in Seafood and Drinking Water. Academic Press, London, pp. 187-209.

Ding, W. X., Shen, H. M. \& Ong, C. N. 2000. Critical role of reactive oxygen species and mitochondrial permeability transition in microcystin induced rapid apoptosis in rat hepatocytes. Hepatology 32:547-55.

Falconer, I. R. 2001. Toxic cyanobacterial bloom problems in Australian waters: risks and impacts on human health. Phycologia 40:228-33.

Fayaz, M., Namitha, K. K., Chidambara Murthy, K. N., Mahadeva Swamy, M., Sarada, R., Salma, K., Subbarao, P. V. \& Ravishankar, G. A. 2005. Chemical composition, iron bioavailability, and antioxidant activity of Kappaphycus alvarezzi (Doty). J. Agric. Food. Chem. 53:792-7.

Frlich, I. \& Riederer, P. 1995. Free radical mechanisms in dementia of Alzheimer type and the potential for antioxidative treatment. Drug Res. 45:443-9.
Fujimoto, K. \& Kaneda, T. 1984. Separation of antioxygenic (antioxidant) compounds from marine algae. Hydrobiologia 116/117:111-3.

Gale, C. R., Martyn, C. N., Winter, P. D. \& Cooper, C. 1995. Vitamin $\mathrm{C}$ and risk of death from stroke and coronary heart disease in cohort of elderly people. Br. Med. J. 310:1563-6.

Herrero, M., Jaime, L., Martín-Álvarez, P. J., Cifuentes, A. \& Ibáñez, E. 2006. Optimization of the extraction of antioxidants from Dunaliella salina microalga by pressurized liquids. J. Agric. Food. Chem. 54:5597-603.

Hettiarachy, N. S., Glenn, K. C., Gnanasambandam, R. \& Johnson, M. G. 1996. Natural antioxidant extract from fenugreek (Trigonella foenumgraecum) for ground beef patties. J. Food Sci. 61:516-9.

Hirata, T., Tanaka, M., Ookie, M., Tsunomura, T. \& Sakaguchi, M. 2000. Antioxidant activities of phycocyanobilin prepared from Spirulina platensis. J. Appl. Phycol. 12:435-9.

Hoffman, R. M. \& Garewal, H. S. 1995. Antioxidants and the prevention of coronary heart disease. Arch. Intern. Med. 155: 241-6.

Huang, H. L. \& Wang, B. G. 2004. Antioxidant capacity and lipophilic content of seaweeds collected from the Qingdao coastline. J. Agric. Food. Chem. 52:4993-7.

Ito, N., Hirose, M., Fukushima, S., Tsuda, H., Shira, T. \& Tatematsu, M. 1986. Studies on antioxidants: their carcinogenic and modifying effects on chemical carcinogenesis. Food Chem. Toxicol. 24:1071-82.

Jayaprakash, G. K., Singh, R. P. \& Sakkaraiah, K. K. 2001. Antioxidant activity of grape seed (Vitis vinifera) extracts on peroxidation method in vitro. Food. Chem. 73:285-90.

Jüttner, F., Leonhardt, J. \& Möhren, S. 1983. Environmental factors affecting the formation of methyloxide, demethylallylic alcohol and other volatile compounds excreted by Anabaena cyclindrica. J. Gen. Microbiol. 129:407-12.

Kaur, H. \& Perkins, J. 1991. The free radical chemistry of food additives. In Aruoma, O. I. \& Halliwell, B. [Eds.] Free Radicals and Food Additives. Taylor and Francis, London, pp. 17-35.

Khotimchenko, S. V. \& Yakovleva, I. M. 2004. Effect of solar irradiance on lipids of the green alga Ulva fenestrata Postels et Ruprecht. Bot. Mar. 47:395-401.

Levy, Y., Haya Zaltsberg, H., Ben-Amotz, A., Kanter, Y. \& Aviram, M. 2000. Dietary supplementation of a natural isomer mixture of beta-carotene inhibits oxidation of LDL derived from patients with diabetes mellitus. Ann. Nutr. Metab. 44:54-60.

Li, X. Y., Chung, I. K., Kim, J. I. \& Lee, J. A. 2005. Oral exposure to Microcystis increases activity-augmented antioxidant enzymes in the liver of loach (Misgurnus mizolepis) and has no effect on lipid peroxidation. Comp. Biochem. Physiol. Part C Toxicol. Pharmacol. 141:292-6.

Lim, S. N., Cheung, P. C. K., Ooi, V. E. C. \& Ang, P. O. 2002. Evaluation of antioxidative activity of extracts from a brown seaweed, Sargassum siliquastrum. J. Agric. Food. Chem. 50:3862-6.

Madhavi, D. L. \& Salunkhe, D. K. 1995. Toxicological aspects of food antioxidants. In Madhavi, D. L., Deshpande, S. S. \& Salunkhe, D. K. [Eds.] Food Antioxidants. Marcel Dekker, New York, pp. 267.

Matsukawa, R., Dubinsky, Z., Kishimoto, E., Masak, K., Masuda, Y., Takeuchi, T., Chihara, M., Yamamoto, Y., Niki, E. \& Karube, I. 1997. A comparison of screening methods for antioxidant activity in seaweeds. J. Appl. Phycol. 9:29-35.

Miranda, M. S., Cintra, R. G., Barros, S. B. \& Filho, J. M. 1998. Antioxidant activity of the microalga Spirulina maxima. Braz. J. Med. Biol. Res. 31:1075-9.

Neuman, I., Nahum, H. \& Ben-Amotz, A. 1999. Prevention of exercise-induced asthma by a natural isomer mixture of betacarotene. Ann. Allergy Asthma Immunol. 82:549-53.

Park, P. J., Heo, S. J., Park, E. J., Kim, S. K., Byun, H. G., Jeon, B. T. \& Jeon, Y. J. 2005. Reactive oxygen scavenging effect of enzymatic extracts from Sargassum thunbergii. J. Agric. Food. Chem. 53:6666-72.

Pinero Estrada, J. E., Bermejo Bescos, P. \& Villar del Fresno, A. M. 2001. Antioxidant activity of different fractions of Spirulina platensis protein extract. Il Farmaco 56:497-500. 
Rao, A. R., Sarada, R., Baskaran, V. \& Ravishankar, G. A. 2006. Antioxidant activity of Botryococcus braunii extract elucidated in vitro models. J. Agric. Food. Chem. 54:4593-9.

Romay, C. \& Gonzalez, R. 2000. Phycocyanin is an antioxidant protector of human erythrocytes against lysis by peroxyl radicals. J. Pharm. Pharmacol. 52:367-8.

Sherwin, E. R. 1978. Oxidation and antioxidants in fat and oil processing. J. Am. Oil Chem. Soc. 55:809-14.

Shimada, K. K., Fujikawa, K. Y. \& Nakamura, T. 1992. Antioxidative properties of xanthan on autoxidation of soybean oil in cyclodextrin. J. Agric. Food. Chem. 40:945-8.

Sigaud-Kutner, T. C. S., Neto, A. M. P., Pinto, E. \& Colepicolo, P. 2005. Diel activities of antioxidant enzymes, photosynthetic pigments and malondialdehyde content in stationary-phase cells of Tetraselmis gracilis (Prasinophyceae). Aquat. Bot. 82:23949 .

Singh, R. P., Chidambara Murthy, K. N. \& Jayaprakash, G. K. 2002. Studies on antioxidant activity of pomegranate peel, seed extracts using in vitro method. J. Agric. Food. Chem. 50:86-9.

Sinha, R. P., Ambasht, N. K., Sinha, J. P. \& Häder, D. P. 2003. Wavelength-dependent induction of a mycosporine-like amino acid in a rice-field cyanobacterium, Nostoc commune: role of inhibitors and salt stress. Photochem. Photobiol. Sci. 2:171-6.

Sukenik, A., Zmora, O. \& Carmeli, Y. 1993. Biochemical quality of marine unicellular algae with special emphasis lipid composition: II Nannochloropsis sp. Aquaculture 117:313-26.
Tedesco, M. A. \& Duerr, O. 1989. Light, temperature and nitrogen starvation effects on the total lipid and fatty acid content and composition of Spirulina platensis UTEX 1928. J. Appl. Phycol. $1: 201-9$.

Ueno, Y., Nagata, S., Tsutsumi, T., Hasegawa, A., Watanabe, M. F., Park, H. D., Chen, G. C., Chen, G. \& Yu, S. Z. 1996. Detection of microcystins, a blue-green algal hepatotoxin, in drinking water sampled in Haimen and Fusui, endemic areas of primary liver cancer in China, by highly sensitive immunoassay. Carcinogenesis 17:1317-21.

Walsh, K., Jones, G. J. \& Dunstan, R. H. 1997. Effect of irradiance on fatty acid, carotenoid, total protein composition and growth of Microcystis aeruginosa. Phytochemistry 44:817-24.

Wanita, A. \& Lorenz, K. 1996. Antioxidant potential of 5- $N$-pentadecylresorcinol. J. Food Process Preserv. 20:417-29.

Wattenberg, L. W. 1986. Protective effects of 2(3)-tert-butyl-4hydroxyanisole on chemical carcinogenesis. Food Chem. Toxicol. 24:1099-102.

Yan, X. J., Chuda, Y., Suzuki, M. \& Nagata, T. 1999. Fucoxanthin as the major antioxidant in Hijikia fusiformis, a common edible seaweed. Biosci. Biotechnol. Biochem. 63:605-7.

Yan, X. J., Li, X. C., Zhou, C. X. \& Fan, X. 1996. Prevention of fish oil rancidity by phlorotannins from Sargassum kjellmanianum. J. Appl. Phycol. 8:201-3. 